\title{
EFEITOS ALELOPÁTICOS DAS FLORES DA Acacia podalyriaefolia A. CUNN.
}

\section{ALLELOPATHIC EFFECTS FROM FLOWERS of Acacia podalyriaefolia A. CUNN.}

ANDRADE, Cláudia Alexandra de; MIGUEL, Marilis Dallarmi; MIGUEL, Obdúlio Gomes; FERRONATO, Marlene de Lourdes; PEITZ, Cristina; CUNICO, Miriam; DIAS, Josiane de Fátima

Gaspari; BALESTRIN, Luciana; KERBER, Vitor Alberto*

\begin{abstract}
Programa de Pós-Graduação em Ciências Farmacêuticas - UFPR. Av. Lothario Meissner, 3400, CEP 80 210-170, Curitiba - Brasil. *Autor para correspondência: e-mail kerber@ufpr.br
\end{abstract}

\section{RESUMO}

Foi investigado o potencial alelopático das flores de Acacia podalyriaefolia A. Cunn.. O estudo da atividade alelopática demonstrou que o extrato etanólico bruto e suas frações diclorometano e acetato de etila tem influência significativa sobre a germinação e crescimento das radículas e hipocótilos de Lactuca sativa. O efeito verificado foi de ativação da germinação das sementes, porém sem o desenvolvimento dos folíolos tornando as mudinhas inviáveis.

Palavras-chave: Acacia podalyriaefolia, Lactuca sativa, alelopatia, plantas medicinais.

\section{ABSTRACT}

The allelopathic potential from the flowers of Acacia podalyriaefolia A. Cunn. was investigated. The study of the allelopathic activity have demonstrated that the crude ethanolic extract and its fractions dichloromethane and ethyl acetate have significant influence in the germination and in the growth of radicle and of the hypocotyls from the Lactuca sativa. The effect was the activation of the germination of the seeds, although the developing of the follicles was prejudiced turning the saplings unviable.

Key words: Acacia podalyriaefolia, allelopathic, Lactuca sativa, medicinal plants.

\section{INTRODUÇÃO}

O termo alelopatia (do grego allelon: mútuo; pathós: prejuízo) foi usado pelo pesquisador alemão Hans Molisch em 1937 para descrever as interações bioquímicas entre as plantas, incluindo também entre estas e os microorganismos (PUTNAM; TANG, 1986; MEDEIROS, 1990). Está relacionado à capacidade de uma planta interferir na germinação de sementes e/ou no crescimento de outras espécies vegetais, influenciando o seu desenvolvimento, por meio de compostos químicos (denominados de aleloquímicos) que estas liberam na atmosfera ou no solo (MEDEIROS, 1990).

Inúmeras substâncias aleloquímicas foram isoladas e identificadas, tendo sido avaliados seus efeitos na germinação, no crescimento, bem como as alterações metabólicas produzidas (RIZVl; RIZVI, 1992).

Diferentes grupamentos químicos (como ácidos fenólicos, cumarinas, terpenóides, flavonóides, alcalóides, taninos, quinonas complexas) podem ser os responsáveis pelos efeitos alelopáticos observados nas plantas (EINHELLIG, 1986; MEDEIROS, 1990).

Compostos fenólicos como os ácidos: benzóico e cinâmico, as cumarinas e os flavonóides estão entre os mais comumente associados com a ação alelopática (EINHELLIG, 1986).

A presença destes compostos é reconhecida como um importante mecanismo ecológico que pode provocar influências significativas no manejo agrícola ou florestal: na dominação de certas espécies vegetais; na sucessão dos plantios e na rotação dos cultivos, podendo favorecer ou prejudicar o desenvolvimento de um determinado produto agrícola e, portanto, afetando sua produtividade (CHOU, 1986; FERREIRA; AQUILA, 2000).

Muitos compostos biologicamente ativos obtidos das plantas já estão sendo usados no controle de ervas daninhas (muitas das quais apresentavam resistência a várias categorias 
de herbicidas usualmente empregados), de insetos e de microorganismos patogênicos, podendo constituir-se em uma alternativa ao uso dos defensivos agrícolas, com menores riscos ao meio ambiente, mantendo um melhor equilíbrio do ecossistema (RIZVI; RIZVI, 1992; CHOU, 1998).

O potencial alelopático da Acacia podalyriaefolia A. Cunn. (LeguminosaeMimosoideae), conhecida como Acácia-mimosa, amplamente cultivada no Brasil como planta ornamental (BURKART, 1979) foi avaliada neste estudo.

\section{MATERIAL E MÉTODOS}

\subsection{Material Vegetal}

Flores da A. podalyriaefolia A. Cunn. foram coletadas em Curitiba, entre os meses de Junho a Setembro de 2002. O material foi autenticado pelo botânico Gert Hatschbach do Museu Botânico Municipal de Curitiba e uma amostra foi herbarizada no mesmo local sob o número 268.219.

\subsection{Preparo dos Extratos}

Flores secas ( $150 \mathrm{~g}$ ) foram extraídas por refluxo com etanol (5 vezes de 20 min. cada). O material foi filtrado usando papel de filtro Whatman $n^{\circ} .1$ e o filtrado foi concentrado em evaporador rotatório sob pressão reduzida, à temperatura não superior a $50{ }^{\circ} \mathrm{C}$ até um volume de $150 \mathrm{ml}$ e, então, centrifugado. O resíduo foi desprezado e o sobrenadante correspondeu ao extrato etanólico bruto (EEB). Além da centrifugação, o desengorduramento do extrato foi completado por meio de partição com hexano em funil de separação. Ao extrato etanólico desengordurado foi acrescentado $100 \mathrm{ml}$ de água destilada. Este extrato hidroalcoólico foi particionado com diclorometano, em extração contínua em aparelho de Sohxlet modificado, resultando na fração diclorometano (FDCM). O extrato hidroalcoólico remanescente foi extraído com acetato de etila em funil de separação, resultando na fração acetato de etila (FAE) (KERBER, 1993). O extrato etanólico bruto e as frações diclorometano e acetato de etila foram reduzidas à secura em evaporador rotatório sob pressão reduzida. Diluições adequadas foram realizadas para se obter as concentrações de 0,400, 0,200, $0,100,0,050$ e $0,025 \mathrm{mg}$ em $5 \mathrm{~mL}$ de metanol as quais, posteriormente foram adicionadas sobre papel watman número 6. Após a evaporação do metanol os testes de alelopatia foram realizados.

\subsection{Preparo das amostras}

As sementes utilizadas na avaliação da germinação e do crescimento foram de Lactuca sativa, classe fiscalizada, cultivar Babá.

Folhas de papel Whatman número 6 embebidas com cada amostra foram acondicionadas em caixas Gerbox e deixadas em estufa a $40^{\circ} \mathrm{C}$ por 24 horas para a evaporação total dos solventes. Cessado este período, água destilada e 40 sementes de Lactuca sativa (em 4 repetições consecutivas de 10 sementes) foram adicionadas em cada uma. O material assim preparado foi utilizado para os testes de germinação e de crescimento. Foram também realizados ensaios controle, nas mesmas condições de ambiente que para 
os experimentos, utilizando apenas água e as sementes.

\subsection{Teste da germinação}

Os efeitos do extrato etanólico bruto e suas frações na germinação das sementes de Lactuca sativa foram avaliados neste teste.

As caixas Gerbox com as amostras e o controle foram colocadas no germinador Mangelsdorf (Biomatic) à temperatura de $20^{\circ} \mathrm{C}$, com limites entre 20,5 e $23^{\circ} \mathrm{C}$. Na verificação da germinação, as sementes eram contabilizadas e aquelas que germinaram foram sendo retiradas. Este procedimento foi realizado diariamente, sempre no mesmo horário, durante 6 dias, dentro de câmara de fluxo laminar para impedir contaminação com microorganismos. Os resultados obtidos foram comparados com aqueles apresentados pelo controle.

\subsection{Teste do crescimento}

Neste teste foi avaliado o efeito que o extrato etanólico bruto e suas frações apresentavam no crescimento da radícula e do caulículo (hipocótilo) da plântula. O material foi processado de modo similar ao teste da germinação, sendo que somente após o $6^{\circ}$ dia de incubação é que as amostras foram analisadas e os resultados comparados com os obtidos para o controle. Foram avaliados os comprimentos da radícula e do caulículo (hipocótilo) das amostras e do controle.

\section{RESULTADOS E DISCUSSÃO}

Quando as sementes foram submetidas ao teste de germinação com os respectivos extratos e frações, observou-se predominância de germinação já nas primeiras 24 horas de incubação (entre 70 a 92\% das sementes com o extrato etanólico bruto; 80 a 92\% com a fração diclorometano; 67 a 89\% com a fração acetato de etila), enquanto que $85 \%$ das sementes do controle germinaram com 48 horas de incubação. Concomitantemente ao estímulo na germinação observado com as sementes em substrato contendo o extrato etanólico bruto e as frações diclorometano e acetato de etila, não houve desenvolvimento de folíolos. Conseqüentemente, a plântula não terá condições de completar seu ciclo de desenvolvimento por não poder realizar a fotossíntese.

Os resultados obtidos para o controle (água) no teste do crescimento foram considerados como 100\%. Os valores obtidos para as amostras foram relacionados a estes controles, permitindo a obtenção do crescimento radicular e caulicular em porcentagem. Os referidos dados foram submetidos à análise de variância e ao teste 't" de Student, com 95\% de confiança. Ainda que o pequeno estímulo no crescimento da radícula e do hipocótilo verificado com o extrato etanólico bruto não seja estatisticamente significativo, não houve desenvolvimento de folíolos nas plântulas perante este substrato. Com a fração diclorometano houve considerável efeito alelopático, apresentando inibição do crescimento radicular e estímulo caulicular. Resultados significativamente diferentes do controle na avaliação do crescimento radicular foram observados com 0,400, 0,200, 0,05 e 0,025 mg desta fração. Inibição de 50\% e 45\% no crescimento da radícula foi obtida, respectivamente, com 0,400 e 0,025 mg da fração diclorometano, cujos efeitos foram estatisticamente similares, diferindo dos resultados obtidos com 0,200 e 0,050 mg (28\% e 18\% de inibição, respectivamente). 
No crescimento do hipocótilo foi verificado estímulo de $18 \%$ com 0,400 mg desta fração. Com as demais frações os efeitos obtidos no crescimento caulicular não foram significativamente diferentes dos obtidos com o controle. Também não houve formação de folíolos nas plântulas com este substrato. Inibição significativa do crescimento da radícula (34\%) e do hipocótilo (23\%) foram observadas com a concentração 0,200 mg da fração acetato de etila. Ainda que com as demais concentrações não tenha havido alteração significativa em relação ao controle, não se observou desenvolvimento de folíolos nas plântulas que se desenvolveram neste substrato.

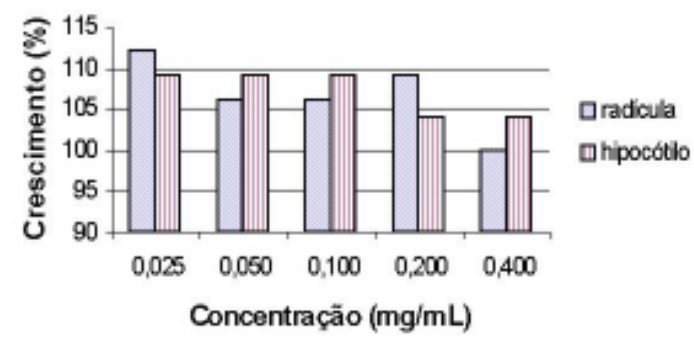

EEB

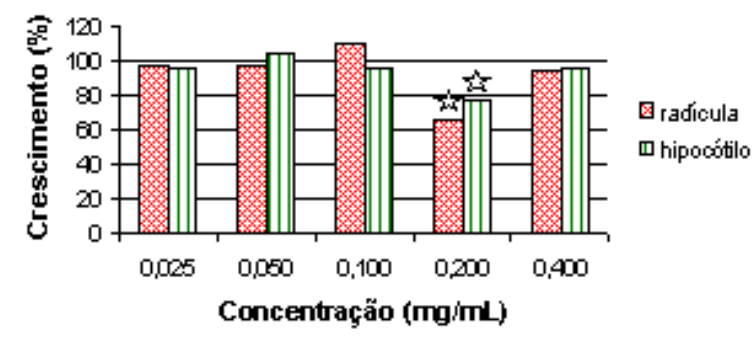

FDM

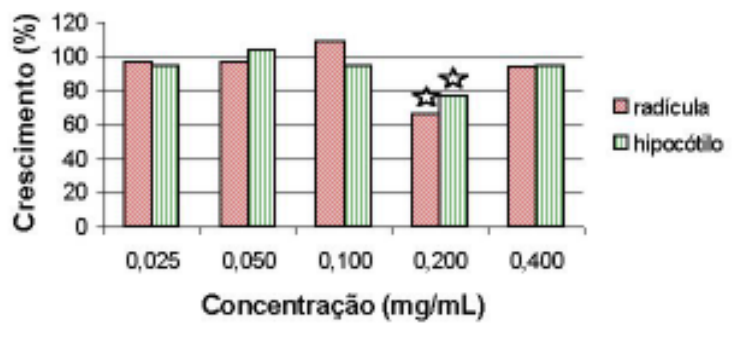

FAE

Figura 1 - Avaliação do crescimento de Lactuca sativa frente ao extrato etanólico bruto (EEB) e às frações diclorometano (FDM) e acetato de etila (FAE) das flores da Acacia podalyriaefolia A. Cunn., comparados ao controle (100\%).

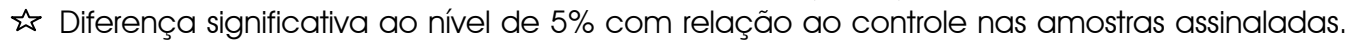

Plântulas anormais, com necrose da radícula, foram observadas nos ensaios com as frações diclorometano e acetato de etila. Estes dados sugerem a presença de aleloquímicos nas amostras, pois conforme afirmam FERREIRA e AQUILA (2000), a presença de substâncias alelopáticas pode induzir ao aparecimento deste efeito. Aliado a isto se observou discrepâncias no crescimento da radícula e do hipocótilo que também poderiam conduzir a obtenção de plântulas anormais as quais provavelmente não conseguiriam completar o seu desenvolvimento. Ainda, a inibição do crescimento radicular pode ocasionar a diminuição de absorção de nutrientes pela raiz, acarretando problemas para o desenvolvimento e sobrevivência da plântula. Concomitantemente, a ausência de desenvolvimento de folíolos nas plântulas que cresceram nos substratos avaliados, reforça o potencial alelopático das frações em estudo, indicando a impossibilidade da plântula completar seu ciclo de desenvolvimento quando findarem os nutrientes da semente por não poder realizar a fotossíntese.

Os resultados obtidos nos testes de germinação e do crescimento sugerem a presença de aleloquímicos nas flores da Acacia podalyriaefolia, conforme já havia sido observado 
com diversas espécies pertencentes a este gênero, havendo efeito alelopático significativo para 0,200 mg da fração acetato de etila e para 0,025 e 0,400 mg da fração diclorometano, onde se evidenciou elevada atividade biológica, possivelmente devido à presença de compostos fenólicos e flavonóides, detectados no screening fitoquímico (MOREIRA, 1979). Este efeito caracterizado para substâncias fenólicas e flavonoídicas foi evidenciado também nos extratos da Acacia nilotica (SWAMINATHAN et al., 1989), da Acacia melanoxylon (GONZÁLES et. al. 1995) e da Acacia confusa (CHOU et al., 1998).

Os resultados até aqui obtidos estimulam a continuidade deste trabalho para avaliar as frações diclorometano e acetato de etila e os compostos fenólicos isolados destas, quanto ao seu potencial alelopático sobre outras espécies vegetais, com aplicação direta na obtenção de matéria-prima vegetal para a produção de fitoterápicos, isenta de resíduos de herbicidas e agrotóxicos de origem sintética. Tal aplicação justifica-se à medida que vem atender as recomendações para o controle de qualidade de drogas na indústria de fitoterápicos, que requer material isento de contaminantes microbianos, biológicos, metais pesados e agrotóxicos, de acordo com a Farmacopéia Brasileira e as recomendações da Organização Mundial de Saúde (WORLD HEALTH ORGANIZATION, 1993; BRASIL, 2000).

\section{REFERÊNCIAS}

BRASIL. Ministério da Saúde. Portaria RDC n. 17, de Fevereiro de 2000. Diário Oficial da República Federativa do Brasil, Brasília, 2000.

BURKART, A . Leguminosas - Mimosoideas. Flora llustrada Catarinense. Itajaí: P. Raulino Reitz, v. 1, p. 17-48, 1979. CHOU, Chang-Hung. The role of allelopathy in subtropical agrosystems in Taiwan. In: PUTNAM, A. R.; TANG, ChungShih. The Science of Allelopathy. Toronto: John Wiley \& Sons, p. 57-73, 1986.

$\mathrm{CHOU}$, Chang-Hung et al. Allelopathic potential of Acacia confusa and related species in Taiwan. Journal of Chemical Ecology, v. 24, n. 12, p. 2131-2150, 1998.

EINHELLIG, F. A. Mechanisms and modes of action of allelochemicals. In: PUTNAM, A.R.; TANG, Chung-Shih. The science of allelopathy. Toronto: John Wiley \& Sons, p. 171-187, 1986.

FERREIRA, A. G.; AQUILA, M. E. Alelopatia: uma área emergente da ecofisiologia. Revista Brasileira de Fisiologia Vegetal, v. 12, p. 175-204, 2000.

GONZALES, L.; SOUTO, X. C.; REIGOSA, M. J. Allelopathic effects of Acacia melanoxilon R. Br. Phyllodes during their decomposition. Forest Ecology, v. 77, n. 1-3, p. 53-63, 1995.

KERBER, V. A. Flavonóides da Acacia longifolia (Andr.) Willd. - Leguminosae-Mimosoideae. Revista Brasileira de Farmácia , v. 74, n. 1, p. 16-18, 1993.

MEDEIROS, A .R. M. Alelopatia. Horti Sul, v. 1, n. 3, p. 27-32, 1990.

MOREIRA, E. A. Contribuição ao estudo fitoquímico de Lobelia hassleri A. Zahlb e Lobelia stellfeladii $R$. Braga. Campanulaceae. Tribuna Farmacêutica, v. 47, n. 1, p. 13-39, 1979.

PUTNAM, A. R.; TANG, Chung-Shih. Allelopathy: state of the science. In: John Wiley \& Sons, p. 1-19, 1986.

RIZVI, S. J. H.; RIZVI, V. Exploitation on allelochemicals in improving crop productivity. In: and applied aspects. 1 ed., Londres: Chapman \& Hall, p. 443-472, 1992.

WORLD HEALTH ORGANIZATION. WHO/PHARM, 93.561, de Fevereiro de 1993. Good Manufacturing Practices for Pharmaceutical Products, 1993. 